\title{
Study of Residual Stress Effect on Hydrogen Diffusion of X-groove Flat Butt Welded Joints
}

\author{
Qianqian Jia, Kaixiang Sun, Hui Liu, Xiaofeng Meng
}

\begin{abstract}
Ships are usually large-welded structures, and residual stress would inevitably occur in the welding process. At present, high-strength steel has been more and more widely used in ship structures, and it has high sensitivity to residual stress. At the same time, in the high temperature during the welding process, the hydrogen-containing compound in the arc welding is decomposed into monoatomic hydrogen, which is dissolved in the molten pool in a large amount. Uneven weld residual stresses in such structures can promote the diffusion and accumulation of hydrogen in the steel, resulting in excess hydrogen at the weld joint. This behavior can lead to hydrogen embrittlement, threatening the safety and reliability of the ship's structure. In this study, a three-dimensional finite element analysis thermodynamic model for the flat butt welding joints of high-strength steel was established, the welding process was simulated, and the distribution law for the welding residual stress field was obtained based on the thermal elastic-plastic theory. Then the sequential coupling calculation of hydrogen diffusion was performed by defining the welding residual stress field of flat butt welding joint of high strength steel as the pre-defined field, and the hydrogen diffusion behavior under the welding residual stress field was obtained based on the theory of residual stress-induced hydrogen diffusion. The results show that the welding residual stress level decreases rapidly with the increase of the weld distance. The welding residual stress affects the hydrogen diffusion behavior, hydrogen is enriched in the zone where the residual stress is high, and the heat affected zone is the region with high residual stress. These results could provide theoretical support for ensuring the safety and reliability of large ship structures.
\end{abstract}

Index Terms - Hydrogen Diffusion, Residual Stress, High-Strength Steel, Numerical Simulation

\section{INTRODUCTION}

Flat butt welding is the most common welding form on ships, usually large welding structures. During the welding process, the hydrogen-containing compound in arc welding decomposes into monoatomic hydrogen at a high temperature in the arc and is dissolved in the molten pool in a large amount. When the molten pool solidifies, a part of the hydrogen escapes, and another part of the hydrogen exists in the weld, forming a gap solid solution with the weld metal. Since the hydrogen radius is small, a part of hydrogen is freely diffused in the crystal lattice of the weld metal to become diffused hydrogen. Another part of the diffusion is concentrated in the voids of the lattice defects, microcracks

Qianqian Jia, School of Naval Architecture and Ocean Engineering, Jiangsu University of Science and Technology, Zhenjiang 212003, China

Kaixiang Sun, School of Naval Architecture and Ocean Engineering, Jiangsu University of Science and Technology, Zhenjiang 212003, China.

Hui Liu, School of Naval Architecture and Ocean Engineering, Jiangsu University of Science and Technology, Zhenjiang 212003, China.

Xiaofeng Meng, School of Naval Architecture and Ocean Engineering, Jiangsu University of Science and Technology, Zhenjiang 212003, China. and non-metallic inclusions, and is combined into molecules, which cannot be freely diffused, and is called residual hydrogen. The chemical potential gradient is the fundamental cause of hydrogen diffusion in steel, and both the hydrogen concentration gradient and the stress gradient can lead to the generation of chemical potential gradient [1]. The main sources of hydrogen in welding are shown as follow: the moisture contained in the coating, the core or the flux in the welding material; the damage to the product packaging, the humid environment or the long storage time can lead to a significant increase in the diffusion hydrogen content; The surface paint, rust, coating, anti-splash compound and grease, surface lubricant of the wire can affect the diffusion hydrogen content; the temperature and humidity of the welding environment have a great influence on the diffusion hydrogen content, and the moisture in the air can enter the arc, thus increase the diffusible hydrogen content[2].

The essence of hydrogen-induced failure is that hydrogen enters the interior of the material and causes crack nucleation and expansion [1]. Hydrogen has different diffusion properties in different metals or in different structures of the same metal. The diffusion rate slows down with decreasing temperature, but also diffuses at room temperature. In different parts of the joint, due to the existence of different plastic deformation, there are different dislocation densities, which will capture different amounts of hydrogen. The diffusion and accumulation of hydrogen in the material are not only related to the heterogeneity of the structure [3], but also related to the stress concentration in the material [4-6]. The results show that hydrogen accumulation in the notched sites such as roots and weld toes will directly affect the generation of cold cracks [2].

Zhang Xianhui et al. [7] determined the diffusion coefficient and solubility of hydrogen in various areas of welded joints by gas phase infiltration method, and based on the extension of Fick's second law, the diffusion of hydrogen in 20MnNiMo steel welded joints was carried out by ABAQUS finite element analysis software. The simulation results show that the hydrogen concentration in the weld metal gradually decreases with time, and the concentration of hydrogen outside the fusion zone undergoes a peak change process. Jiang Wenchun et al. [8-10] based on the basic theory of hydrogen diffusion induced by welding residual stress, a coupled finite element calculation program for hydrogen diffusion under welding residual stress was developed by the finite element software ABAQUS. The distribution of hydrogen-diffusion induced by welding residual stress in $16 \mathrm{MnR}$ steel liquefied petroleum balloon tank welded joints under wet hydrogen sulfide environment was numerically simulated and compared with hydrogen diffusion under unstressed state. The results show that the welding residual stress is one of the main reasons leading to the accumulation of hydrogen in the welded joint. Lv Liangxinbu et al. [11] 
used COMSOL Multiphysics to numerically simulate the stress and internal hydrogen redistribution in titanium alloy welds in the deep sea environment based on differential equations. The results show that the welding process will generate residual stress at the weld, and under the action of residual stress, hydrogen will be enriched in the high stress region and finally stabilized.

It can be seen from the above literatures that most of the researches are on the hydrogen diffusion of the welded joints of pressure vessels or pipeline steels in the field of chemical engineering, while there are few researches on the hydrogen diffusion of the welded structures in the field of ships. Therefore, the results obtained in this paper on the influence of residual stress on hydrogen diffusion in the most common butt welding joints of ship structure laid a foundation for the study on the influence of residual stress on hydrogen crack.

\section{BASIC THEORY AND ANALYTICAL METHODS}

\section{A. Basic theory}

The diffusion phase should satisfy the law of mass conservation in diffusion [12]:

$$
\int_{V} \frac{\mathrm{d} e}{\mathrm{~d} t} \mathrm{~d} V+\int_{S} n \cdot J d S=0
$$

Where: $V$ represents the volume; $S$ represents the surface of the volume $V ; n$ represents the vector of the vertical surface $S$; $J$ is the concentration flow of the diffusion phase; $n \cdot J$ represents the concentration flow leaving the $S$ surface.

In a heterogeneous medium, the constitutive equation for hydrogen diffusion caused by a chemical potential gradient is:

$$
\begin{gathered}
l=-s D \cdot\left[\frac{\partial \varphi}{\partial x}+k_{g} \frac{\partial}{\partial x}\left(\ln \left(\theta-\theta_{z}\right)\right)+k_{p} \frac{\partial p}{\partial x}\right] \\
\varphi=\frac{c}{g}
\end{gathered}
$$

where $D$ represents the diffusion coefficient of hydrogen, $\varphi$ represents the hydrogen activity, $c$ represents the concentration of hydrogen, $s$ represents the solubility of hydrogen, $k_{g}$ represents the "Soret effect" coefficient driven by the temperature gradient, $\theta$ represents the temperature, $\theta_{z}$ represents the absolute temperature zero on the temperature scale used, $k_{p}$ represents the stress coefficient driven by the stress gradient, and $P=-\operatorname{trace}(\sigma) / 3$ is the equivalent stress.

$$
P=-\frac{\sigma_{11}+\sigma_{22}+\sigma_{33}}{a}
$$

Assuming that the ambient temperature is constant and the influence of the temperature gradient on hydrogen diffusion is not taken into account, (2) becomes (5), and the stress influence factor $k_{\mathrm{p}}$ can be calculated using (6).

$$
\begin{array}{r}
l=-s D \cdot\left(\frac{\partial \varphi}{\partial x}+k_{p} \frac{\partial p}{\partial x}\right)_{V_{H}} \\
k_{p}=\varphi \cdot \frac{15)}{R\left(\theta-\theta_{z}\right)}(6)
\end{array}
$$

where $R$ is the general gas constant and $V_{H}$ is the partial molar volume of hydrogen in steel.

\section{B. Analysis steps}

The sequential coupling calculation steps and the hydrogen diffusion process under the welding residual stress field are shown in Fig. 1. Firstly, the welding temperature field is calculated, and then the temperature field result is used as the pre-input to calculate the welding stress field. Finally, the result of the welding stress field is used as the sequential coupling calculation of hydrogen diffusion for the predefined field of hydrogen diffusion [13]. In this paper, ABAQUS finite element software was used for numerical simulation of hydrogen diffusion induced by welding residual stress.

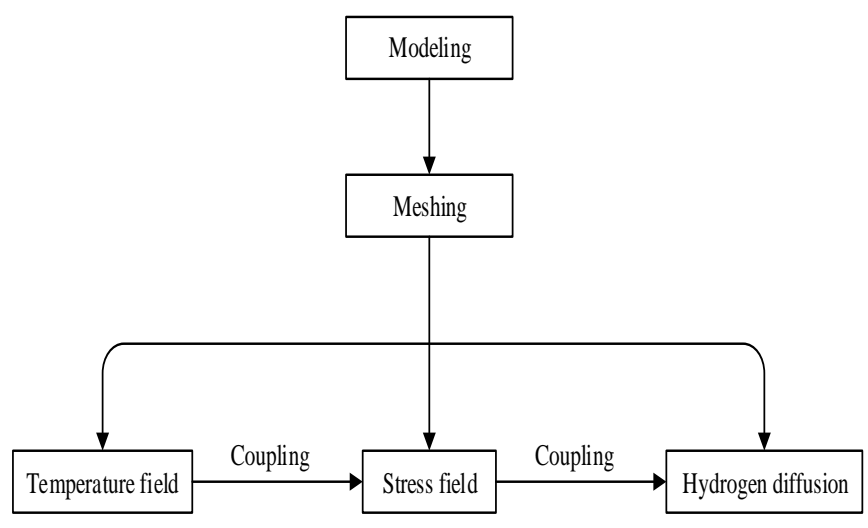

Fig. 1. Steps for numerical simulation of hydrogen diffusion

\section{NUMERICAL SIMULATION OF THE RESIDUAL STRESS FIELD}

\section{A. Finite Element Model}

A welded plate of high-strength steel was formed by butt welding two plates with a size of $250 \mathrm{~mm} \times 125 \mathrm{~mm} \times 20 \mathrm{~mm}$, and X-type groove was used in the welded plate. The sketch of the welded joint was presented in Fig. 2. In this paper, a double-sided continuous weld was used according to the thickness of the plate, and the weld is simplified to five layers along the thickness direction, and the geometric model of the welded plate was shown in Fig. 3 .

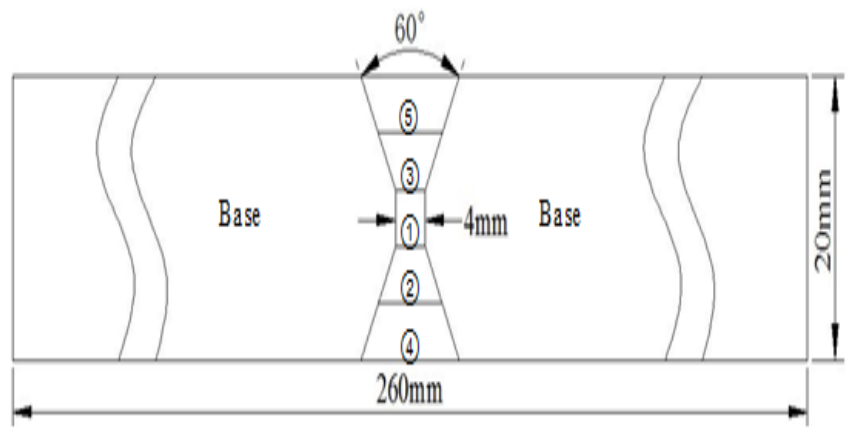

Fig. 2. Sketch of the welded joint.

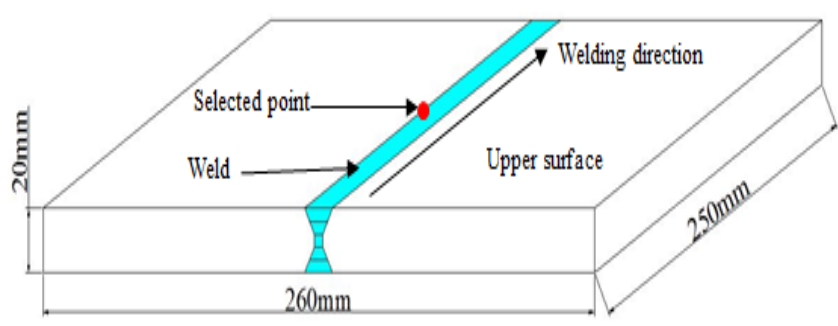

Fig. 3. Geometric model of the welded plate.

\section{B. Thermal Physical Properties and Mechanical Properties}

The flat butt welded joint (Fig. 3) was made of high-strength steel, and the thermal physical properties of this material are shown in Table I . The stress-strain characteristics at different temperatures are shown in Fig. 4 
Table I . Physical properties of the joint material.

\begin{tabular}{|c|c|c|c|c|c|}
\hline $\begin{array}{l}\text { Temper } \\
\text { ature }\end{array}$ & $\begin{array}{l}\text { Elasti } \\
\text { c } \\
\text { modul } \\
\text { us }\end{array}$ & $\begin{array}{l}\text { Poisson' } \\
\text { s ratio }\end{array}$ & $\begin{array}{l}\text { Thermal } \\
\text { expansion } \\
\text { coefficien } \\
t\end{array}$ & $\begin{array}{l}\text { Heat } \\
\text { transfer } \\
\text { coefficien } \\
\mathrm{t}\end{array}$ & $\begin{array}{l}\text { Specific } \\
\text { heat }\end{array}$ \\
\hline${ }^{\circ} \mathrm{C}$ & $\mathrm{MPa}$ & & $1 /{ }^{\circ} \mathrm{C}$ & $\mathrm{W} /\left(\mathrm{m} \cdot{ }^{\circ} \mathrm{C}\right)$ & $\mathrm{J} /\left(\mathrm{kg} \cdot{ }^{\circ} \mathrm{C}\right)$ \\
\hline 20 & $\begin{array}{ll}2.1 & \times \\
10^{5} & \end{array}$ & 0.3 & $1.1 \times 10^{-5}$ & 46 & - \\
\hline 200 & $\begin{array}{l}2.06 \times \\
10^{5}\end{array}$ & 0.3 & $\begin{array}{l}1.22 \\
10^{-5}\end{array}$ & 45 & 550 \\
\hline 400 & $\begin{array}{l}1.71 \times \\
10^{5}\end{array}$ & 0.3 & $\begin{array}{l}1.35 \\
10^{-5}\end{array}$ & 41 & 610 \\
\hline 600 & $\begin{array}{l}0.87 \times \\
10^{5}\end{array}$ & 0.3 & - & 35 & 710 \\
\hline 800 & $\begin{array}{l}0.39 \times \\
10^{5}\end{array}$ & 0.3 & $\begin{array}{l}1.48 \\
10^{-5} \\
\end{array}$ & 24 & 865 \\
\hline
\end{tabular}

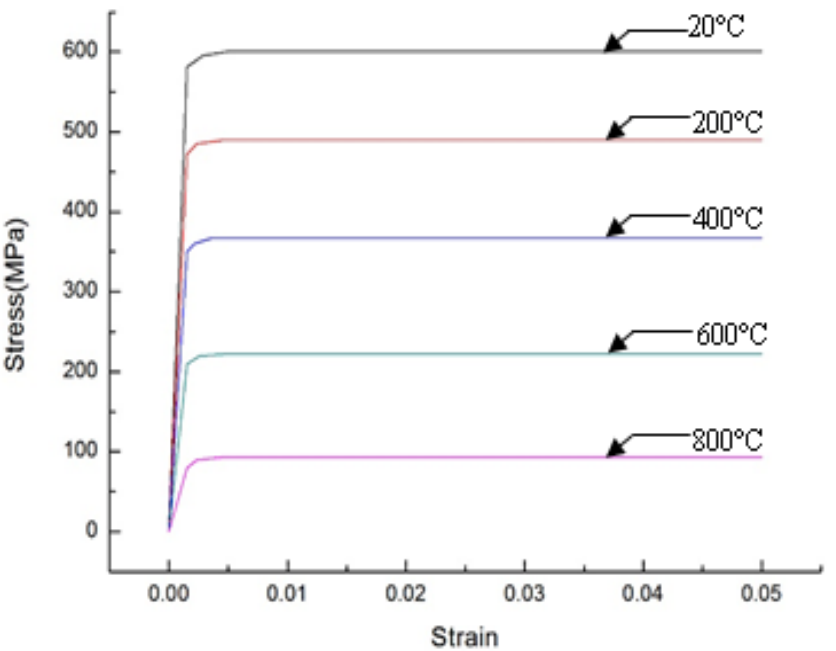

Fig. 4. Stress-strain characteristics of high-strength steel material

\section{Meshing and Boundary Conditions}

The finite element meshing is shown in Fig. 5, with a total of 25,245 nodes and 22,000 elements

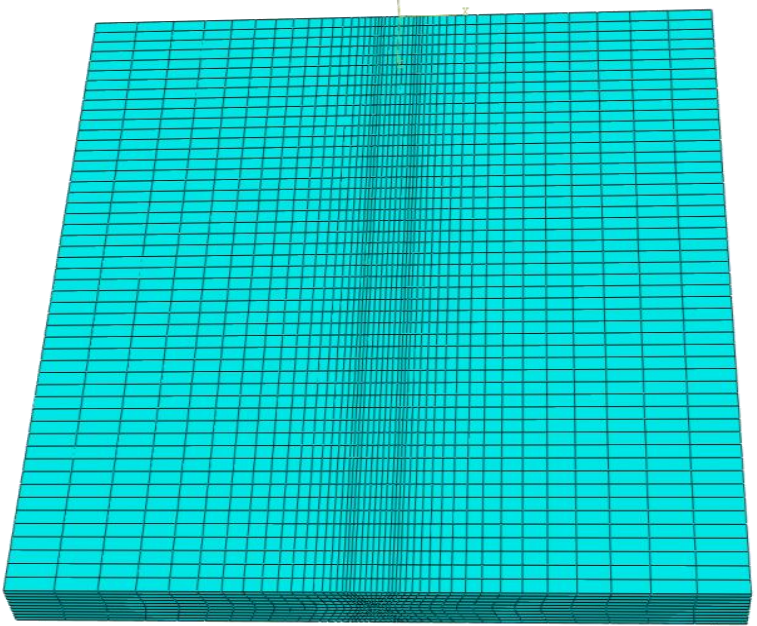

Fig. 5. Finite element meshing.

In the analysis of temperature field, the initial temperature and the ambient temperature were both set to $20^{\circ} \mathrm{C}$, and the convection heat release coefficient was set to $25 \mathrm{~W} / \mathrm{m}^{2} \cdot{ }^{\circ} \mathrm{C}$. In the analysis of stress field, in order to simulate actual conditions, the four sides of the welded plate were rigidly fixed.

\section{Welding Process Parameters}

The welding parameter for simulation is shown in Table II , and the welding thermal efficiency constant was 0.75 . A double ellipsoid heat source was used, as shown in Fig. 6. The parameters of double ellipsoid heat source are shown as follow: $a=0.008 \mathrm{~m}, b=0.006 \mathrm{~m}, c_{f}=0.0032 \mathrm{~m}, c_{y}=0.0064$ $\mathrm{m}, f_{1}=0.8$, and $f_{2}=1.2$.

Table II. Welding procedure.

\begin{tabular}{llll}
\hline Welding layer & $\begin{array}{l}\text { Voltage } \\
\text { V }\end{array}$ & $\begin{array}{l}\text { Current } \\
\mathrm{A}\end{array}$ & $\begin{array}{l}\text { Speed } \\
\mathrm{mm} / \mathrm{s}\end{array}$ \\
\hline 1 & 18 & 106 & 2.5 \\
2 & 18 & 106 & 3 \\
3 & 22 & 166 & 3 \\
4 & 22 & 166 & 3 \\
5 & 30 & 210 & 3 \\
\hline
\end{tabular}

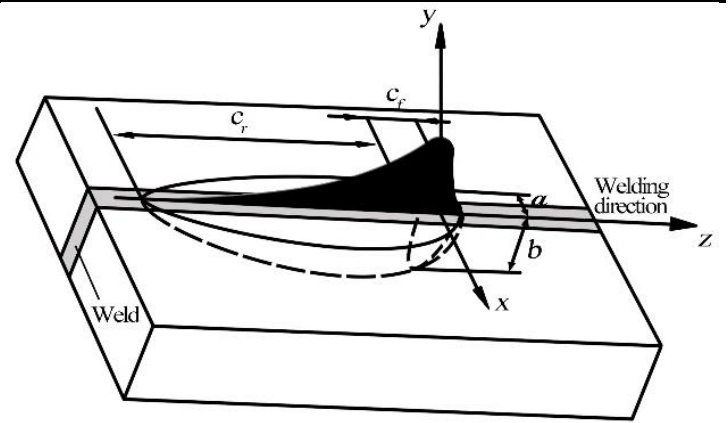

Fig. 6. Double-ellipsoid heat source model.

\section{E. Calculation of the Welding Residual Stress Field}

The life-and-death element technique was used for the numerical simulation of residual stress field in butt welded joint of flat plate. The temperature field after welding is shown in Fig. 7.

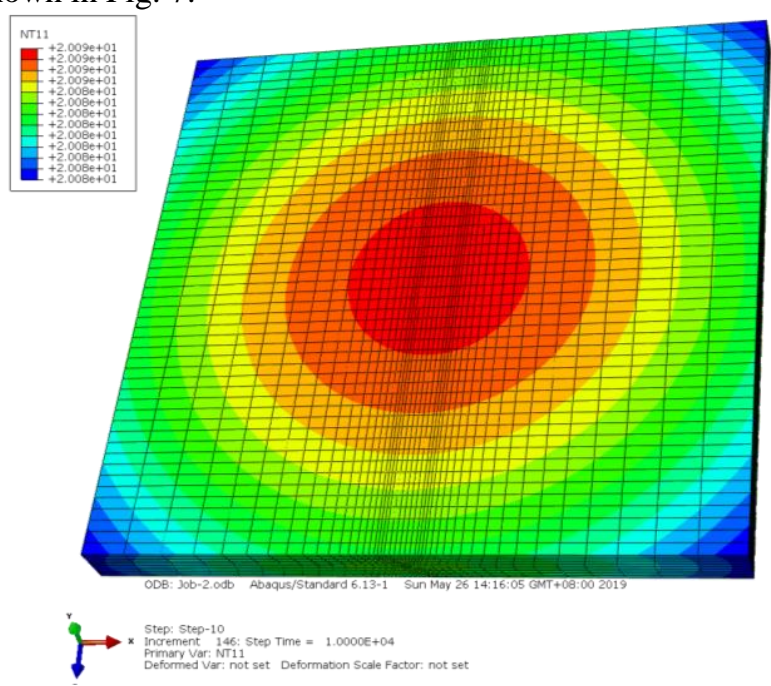

Fig. 7. Temperature field.

The temperature change curve at a selected point (Fig. 3) on the upper surface near the last weld is shown in Fig. 8. It can be seen from Fig. 8 that at a certain point in the welding process of the last weld, the maximum value of the welding temperature was reached, and the maximum value was about $1500{ }^{\circ} \mathrm{C}$, and then cooled rapidly to room temperature. Before reaching the maximum temperature, the point has a maximal 
value, because the heat source is close to the last weld when welding the weld adjacent to the last weld, so that its temperature is higher. Then, when welding the penultimate weld, the temperature of the point decreases. On the temperature curve, it shows a bimodal curve, which first reaches the maximal value, then falls back and then rises to the maximum value. This is consistent with the actual welding process.

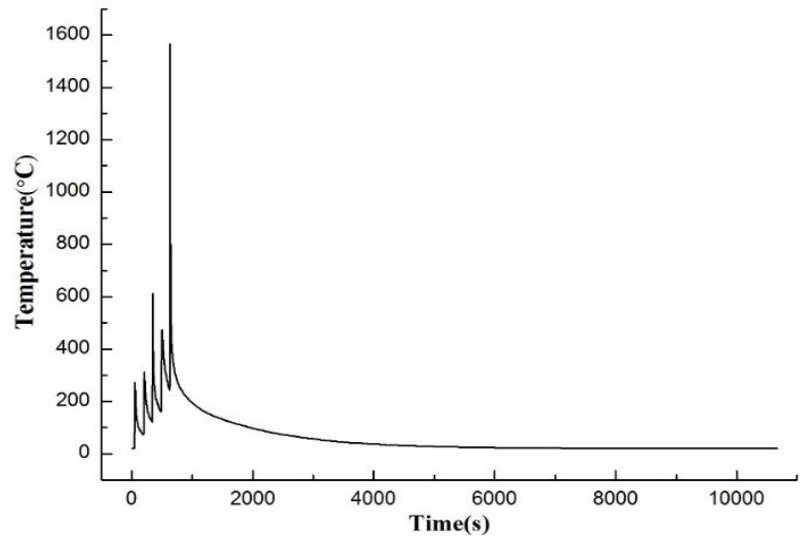

Fig. 8. Temperature curve of a point on the upper surface.

The results of temperature field were used as pre-input to calculate the stress field, and the residual stress distribution of butt welded joint of flat plate is obtained, as shown in Fig. 9. Among them, $\sigma_{x}$ is the transverse residual stress, which is $\sigma_{11}$ in (4); $\sigma_{y}$ is the residual stress in the thickness direction, which is $\sigma_{22}$ in (4); $\sigma_{z}$ is the longitudinal residual stress, which is $\sigma_{\text {a }}$ in (4); and $P_{g}$ is the residual stress component that affects hydrogen diffusion, which is $P$ in (4). Thus, in accordance with (4):

$$
P_{s}=-\frac{\sigma_{x}+\sigma_{y}+\sigma_{x}}{a}
$$

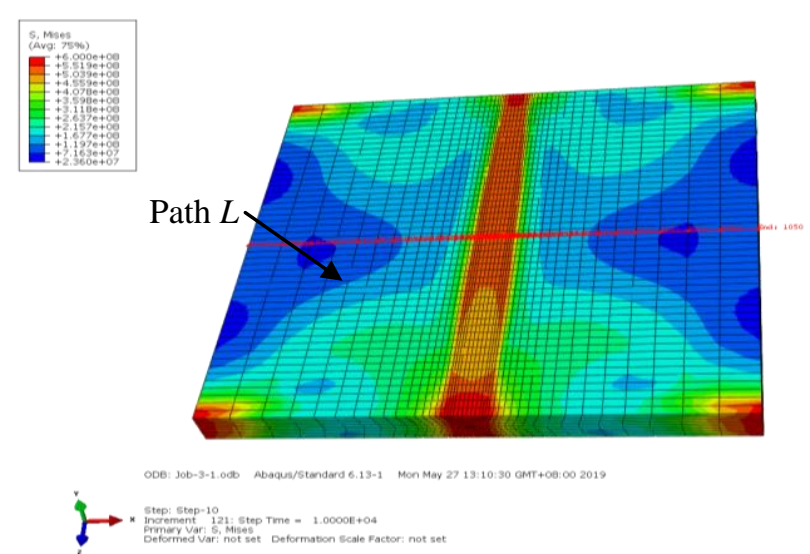

(a) $\sigma$

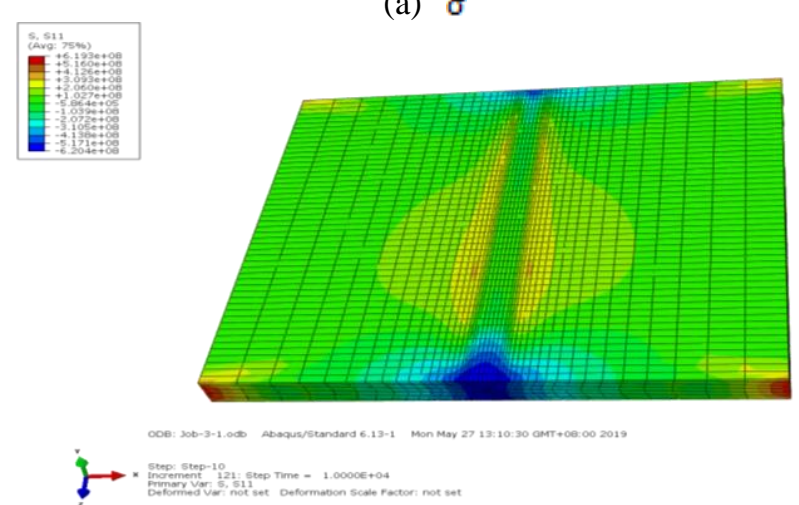

(b) $\sigma_{x}$

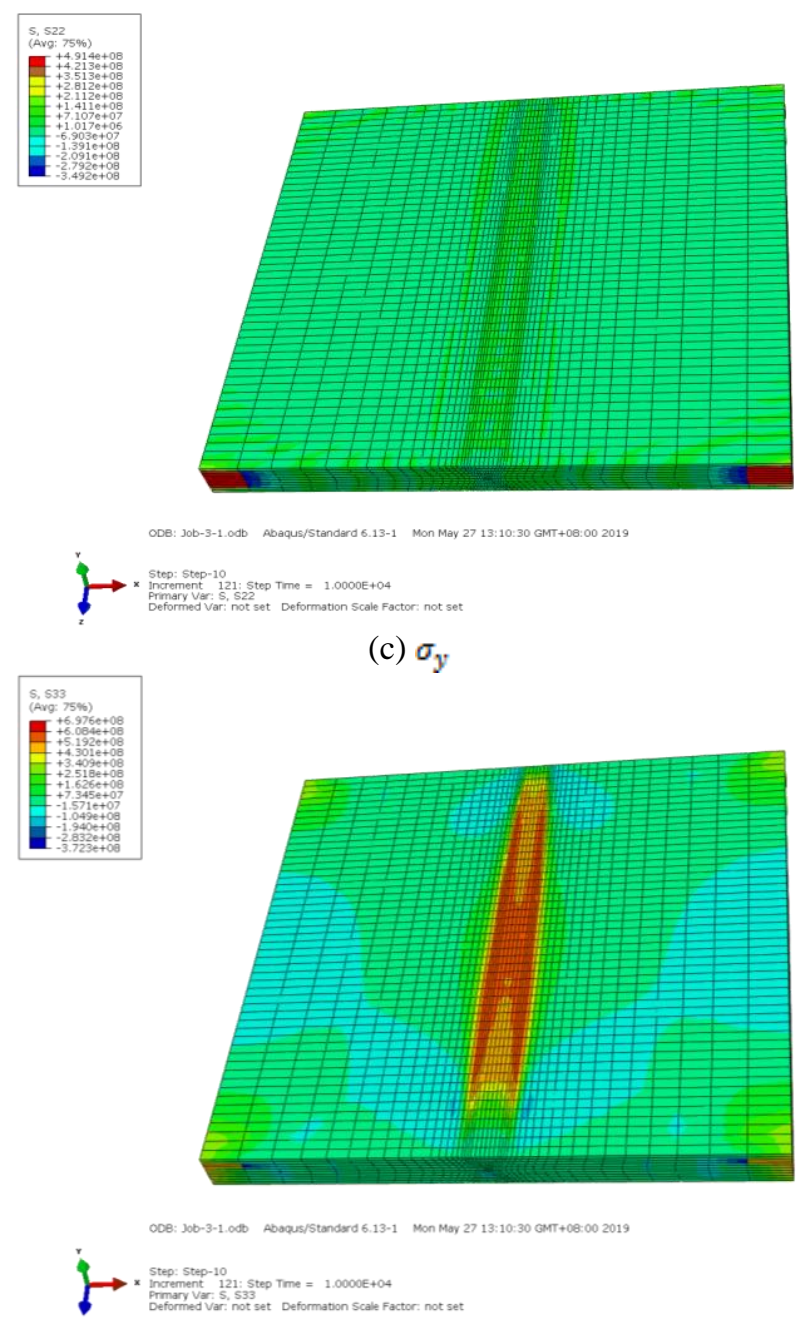

(d) $\sigma_{z}$
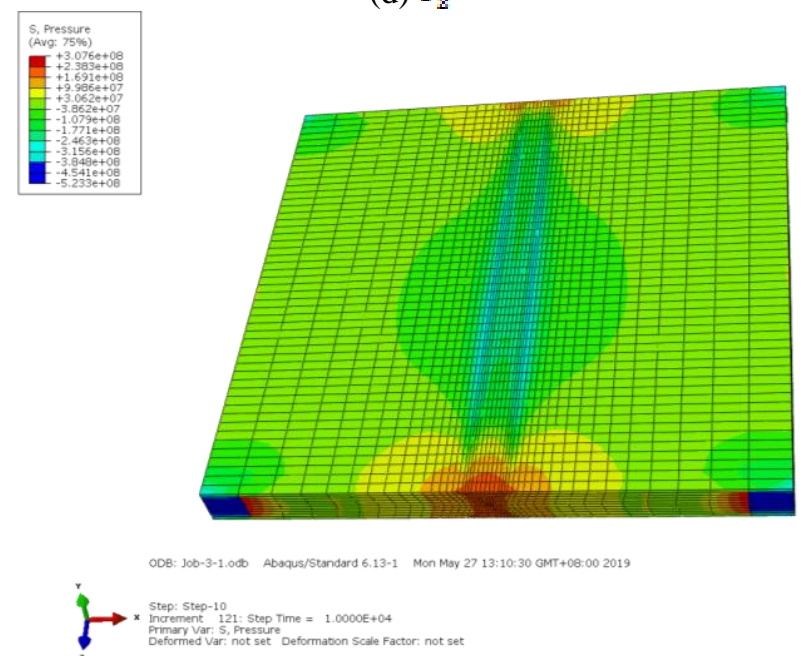

(e) $P_{g}$

Fig. 9. Residual stress distributions.

Fig. 10 (a) shows the residual stress $\sigma_{L}$ along path $L$ of the butt welded joint of the plate, and path $L$ is the center line of the plate width on the upper surface where the last weld is located, as shown in Fig. 9(a). Fig. 10 (b) shows the transverse residual stress $\sigma_{L x}$ along path $L$ on the butt welded joint of the plate. Fig. 10 (c) shows the longitudinal residual stress $\sigma_{L z}$ along path $L$, Fig. 10 (d) shows the residual stress in the thickness direction $\sigma_{L y}$ along path $L$, and Fig. 10 (e) shows 
the residual stress component that affects hydrogen diffusion $P_{L s}\left(P_{L s}=-\frac{\sigma_{L x}+\sigma_{L y}+\sigma_{L x}}{a}\right)$ along path $L$.

As shown in Fig. 9 and Fig. 10, on path $L$ of the butt welded joint:

(1) The maximum value of residual stress $\sigma_{L}$ is $529 \mathrm{MPa}$, which was located in the weld toe and close to the yield stress of the material. As the distance from the weld increases, the level of weld residual stress decreases rapidly;

(2) The transverse residual stress $\sigma_{L X}$ exhibits a symmetric bimodal distribution, and the maximum value appears in the heat affected zone, which is about $288 \mathrm{MPa}$ and is tensile stress;

(3) The maximum value of longitudinal residual stress $\sigma_{L z}$ appears in the heat affected zone, which is about 597 $\mathrm{MPa}$ and is tensile stress;

(4) The maximum value of residual stress in the thickness direction $\sigma_{L y}$ appears in the heat-affected zone, which is about 19.3 MPa and is compressive stress;

(5) The maximum value of residual stress component that affects hydrogen diffusion $P_{L s}$ appears in the heat-affected zone, which is about $275 \mathrm{MPa}$ and is tensile stress.

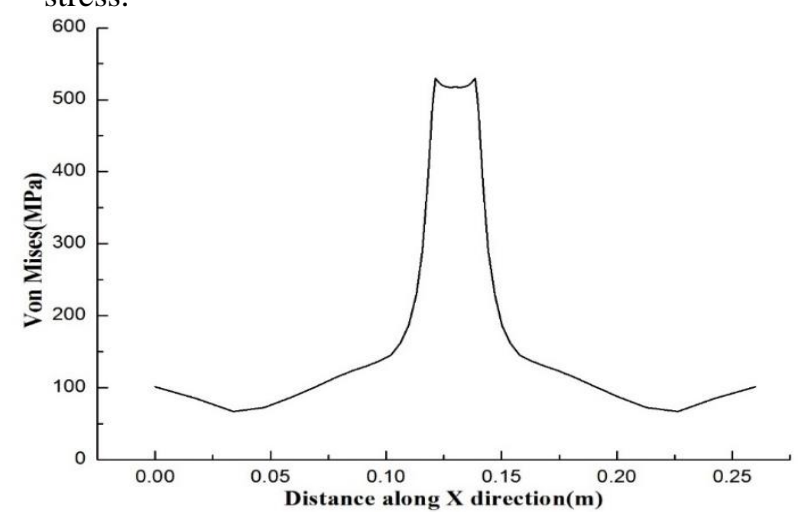

(a) $\sigma_{L}$

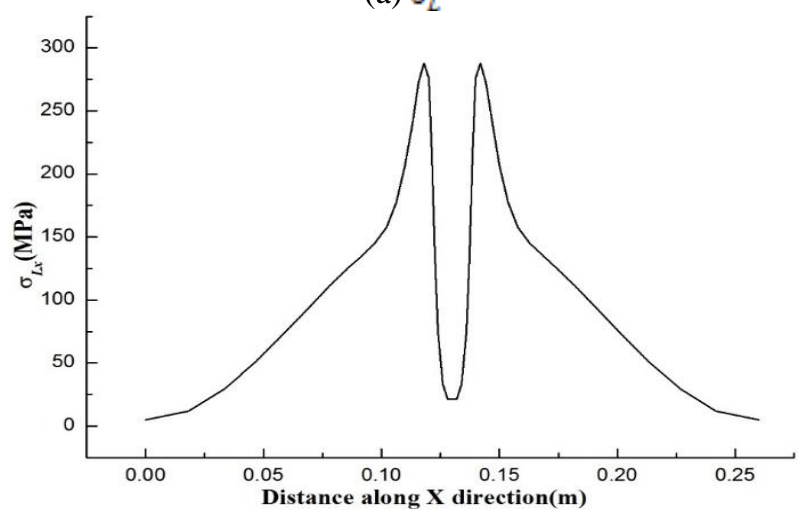

(b) $\sigma_{L x}$

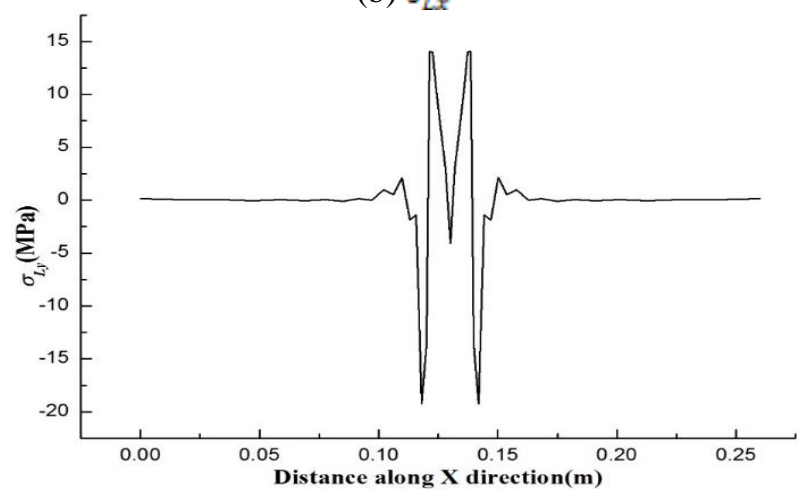

(c) $\sigma_{L y}$

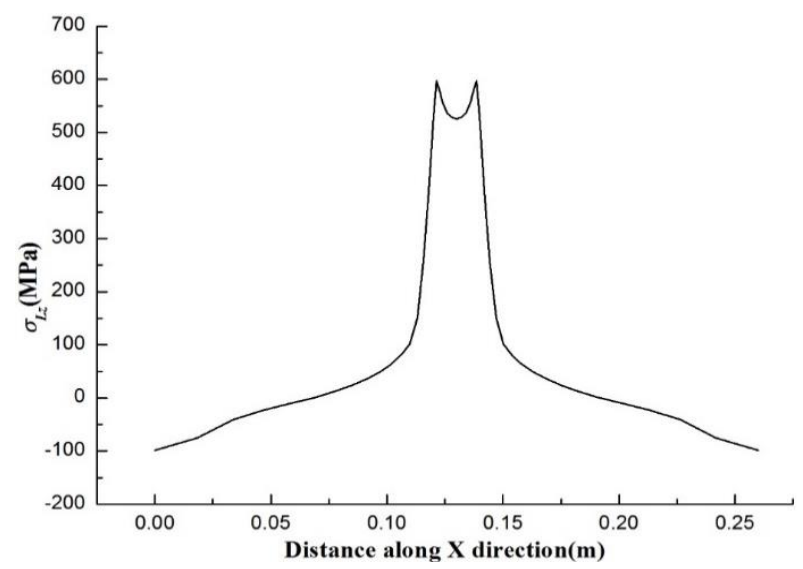

(d) $\sigma_{L z}$

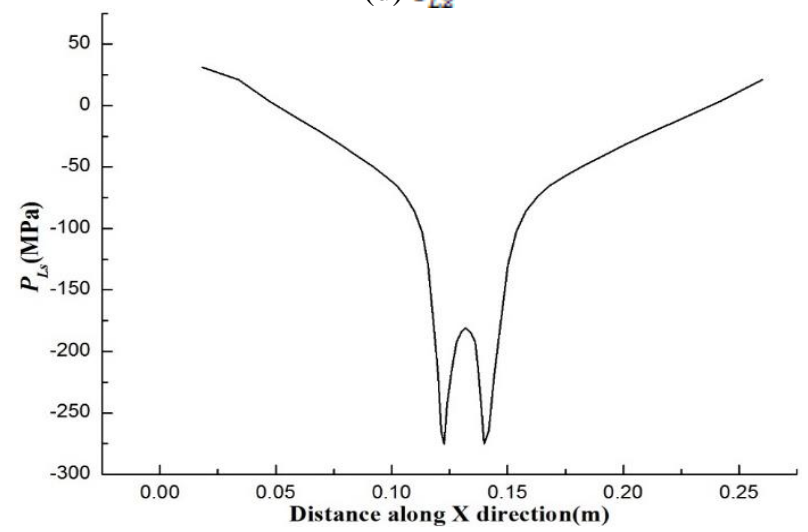

(e) $R_{L s}$

Fig. 10. Stress distribution curves along path $L$.

\section{ANALYSIS OF HYDROGEN DIFFUSION}

In the hydrogen diffusion analysis, the hydrogen activity $\varphi$ is the parameter characterizing the boundary condition. The main source of hydrogen in the butt welded joint of flat plate (Fig. 3) is the electrode. According to the test results, the hydrogen concentration $c$ at the weld is $0.1233 \mathrm{ppm}$ and the solubility $s$ is 0.078 . Thus, according to (3), the hydrogen activity $\varphi$ at the weld is 1.581 . The distribution of hydrogen in the butt welded plate before diffusion, during diffusion and after diffusion were obtained, as shown in Fig. 11, Fig. 12 and Fig. 13. Fig. 14 shows the distribution curves for the hydrogen concentration before and after diffusion along path $L$ (Fig. 9(a))

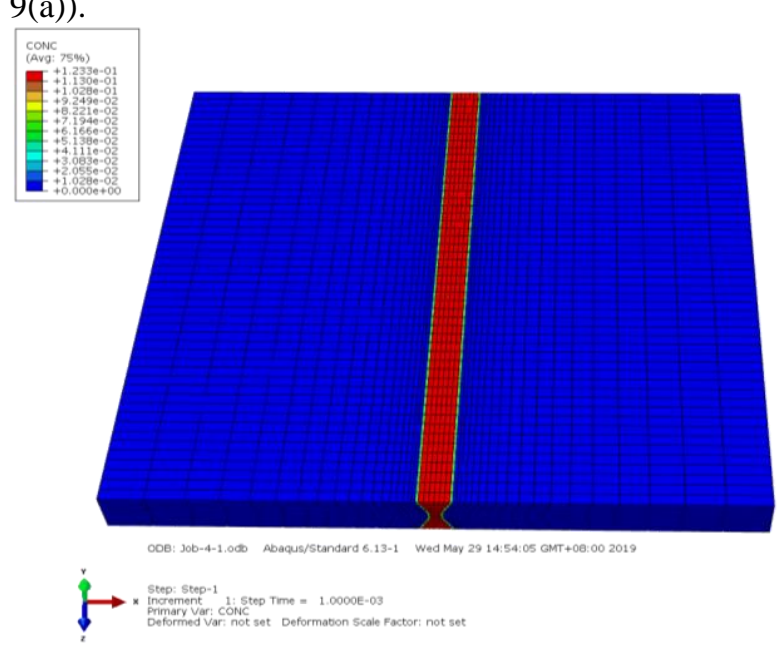

Fig. 11. Hydrogen concentration before diffusion. 


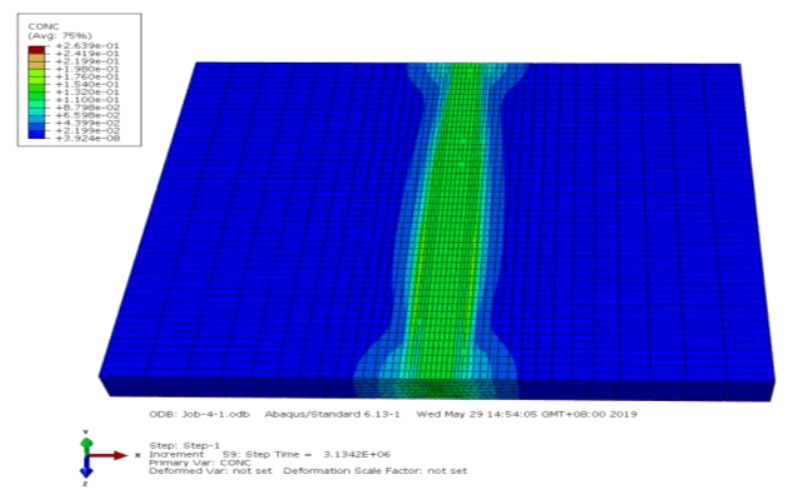

Fig. 12. Hydrogen concentration during diffusion.

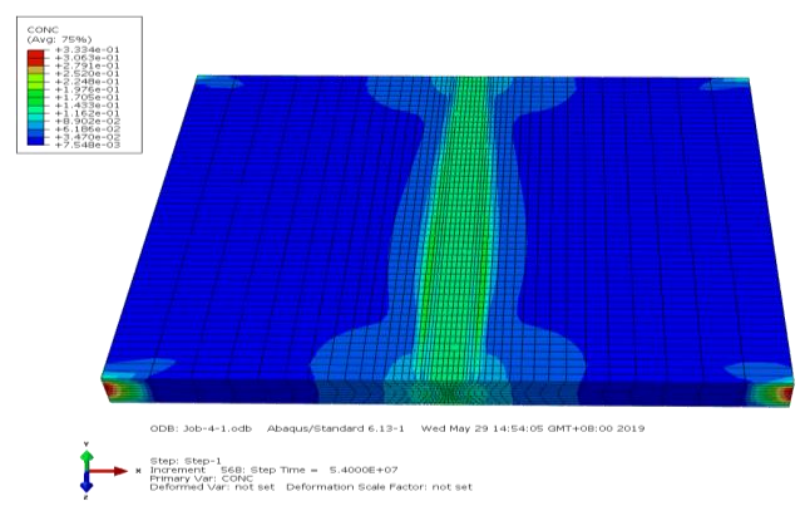

Fig. 13. Hydrogen concentration after diffusion.

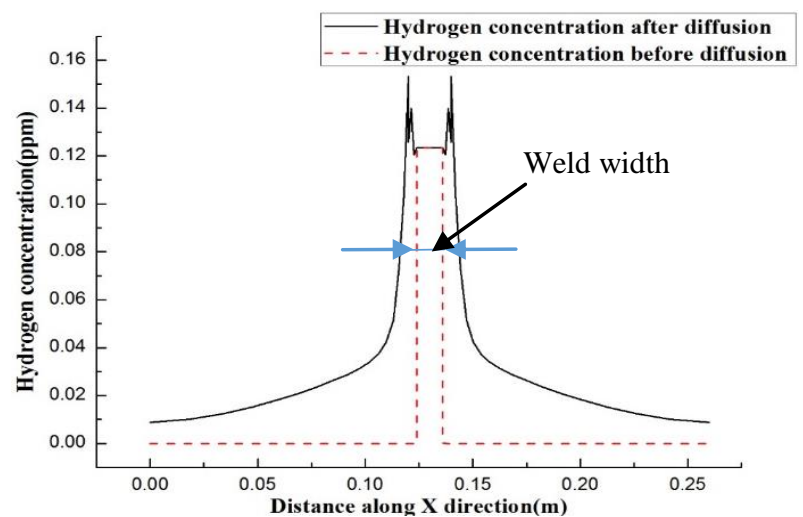

Fig. 14. Hydrogen concentration before and after diffusion along path $L$.

As shown in Figs. 11 to 14, the hydrogen before diffusion is mainly concentrated at the weld and the concentration is $0.1233 \mathrm{ppm}$. The concentration of hydrogen after diffusion reached the highest in the heat affected zone, with a maximum of $0.1532 \mathrm{ppm}$.

The results in Fig. 10 (e), Fig. 13, and Fig. 14 show that under the action of residual stress, hydrogen is concentrated in the high stress region, and after a period of time, it is stabilized. The distribution law of hydrogen concentration is basically consistent with the residual stress distribution law. And the hydrogen concentration is higher in the region with higher tensile stress. Far away from the weld and heat affected zone, the diffusive hydrogen concentration is gradually reduced. In the heat-affected zone, the tensile stress is the largest and the concentration of diffusive hydrogen is the highest.

It can be seen from the above analysis that due to the existence of welding residual stress, hydrogen will be diffused and aggregated into the weld and the heat affected zone, so that the hydrogen concentration in the weld and the heat affected zone is too high. Therefore, in the subsequent research, the area will be focused on, because this area is easy to produce hydrogen-induced cracking and threatens the safety and reliability of ship use.

\section{CONCLUSIONS}

In this paper, hydrogen diffusion under the residual stress of $\mathrm{X}$-groove flat butt welded joints of in high-strength steel was analyzed, and the following main conclusions are listed.

(1) The welding residual stresses in the weld and the heat-affected zone are larger, with the maximum value approaching the yield strength of the material, and the level of the residual stress decreases rapidly as the distance from the weld increases.

(2) Hydrogen diffuses and accumulates in the high stress zone under the effect of welding residual stress. The final maximum hydrogen concentration appears in the heat-affected zone which coincides with the maximum level of residual stress. Therefore, hydrogen-induced cracking can easily occur in this area, adversely affecting the safety and reliability of the welded structure.

\section{REFERENCES}

[1] Zhang, T.: Study on hydrogen embrittlement of welded joints of X80 steel in high-pressure coal-to-gas pipeline. China University of Petroleum (East China) (2016).

[2] GB3965-2012. Determination of diffusible hydrogen in deposited metal.

[3] Xue, J., Shi, C., Yu, Q., Li, M.: Diffusion of hydrogen in different composition of steel. Trans. Chin. Weld. Inst. 19, 261-266 (1998)

[4] Zhang, T., Yao, Y., Chu, W., Qiao, L.: Relationship between hydrogen-induced additive stress and threshold cracking stress for a pipeline steel. Acta Metall. Sin. 38, 844-848 (2002).

[5] Turnbull, A., Ferriss, D.H., Anzai, H.: Modelling of the hydrogen distribution at a crack tip. Mater. Sci. Eng. A 206, 1-13 (1996).

[6] Hughey, M.P., Cook, R.F.: Hydrogen diffusion as the rate-limiting mechanism of stress development in dielectric films. Appl. Phys. Lett. 85, 404-406 (2004).

[7] Ohmi, T., Yokobori, T., Takei, K., Konishi, Y.: The analysis of hydrogen diffusion behaviors coupled with the analysis of heat transfer around the heat affected zone of welding. In: ASME 2014 Pressure Vessels and Piping Conference, Volume 6B, pp. V06BT06A018. American Society of Mechanical Engineers (2014).

[8] Jiang, W., Gong, J., Tang, J., Chen, H., Tu, S.: Numerical simulation of hydrogen diffusion under welding residual stress. Trans. China Weld. Inst. 27, 57-60 (2006)

[9] Jiang, W.C., Gong, J.M., Tang, J.Q., Chen, H., Tu, S.T.: 3-D finite element analysis of the effect of welding residual stress on hydrogen diffusion in hydrogen contained environment. Acta Metall. Sin. 20, 347-354 (2007).

[10] Jiang W., Gong, J., Tang, J., Chen, H., Tu, S.: Finite element simulation of the effect of welding residual stress on hydrogen diffusion. Acta Metall. Sin. 42, 1221-1226 (2006)

[11] Lv, L., Zheng, B., Xi, Q.: Numerical analysis of hydrogen diffusion under residual stress at welded joints. In: 2017 Fourth Marine Materials and Corrosion Protection Conference (2017).

[12] Abaqus 6.13. http://dsk.ippt.pan.pl/docs/abaqus/v6.13/index.html

[13] Yan, C., Zhang, G., Liu, C.: Numerical simulation of hydrogen distribution in welded joint of X80 pipeline steel. Trans. China Weld. Inst. 36, 103-107 (2015).

Qianqian Jia, School of Naval Architecture and Ocean Engineering, Jiangsu University of Science and Technology, Zhenjiang 212003, China.

Kaixiang Sun, School of Naval Architecture and Ocean Engineering, Jiangsu University of Science and Technology, Zhenjiang 212003, China.

Hui Liu, School of Naval Architecture and Ocean Engineering, Jiangsu University of Science and Technology, Zhenjiang 212003, China.

Xiaofeng Meng, School of Naval Architecture and Ocean Engineering, Jiangsu University of Science and Technology, Zhenjiang 212003, China. 